\begin{tabular}{|c|c|}
\hline ANGIES & Angles \\
\hline $\begin{array}{l}\text { NEW PERSPECTIUE5 } \\
\text { ANGLOPHONE WORLD }\end{array}$ & New Perspectives on the Anglophone World \\
\hline & $\begin{array}{l}7 \mid 2018 \\
\text { Digital Subjectivities }\end{array}$ \\
\hline
\end{tabular}

\title{
Alexa and the Intersectional Interface
}

\section{Luke Munn}

\section{(2) OpenEdition}

\section{Journals}

Electronic version

URL: https://journals.openedition.org/angles/861

DOI: 10.4000/angles.861

ISSN: 2274-2042

\section{Publisher}

Société des Anglicistes de l'Enseignement Supérieur

\section{Electronic reference}

Luke Munn, "Alexa and the Intersectional Interface", Angles [Online], 7 | 2018, Online since 01

November 2018, connection on 08 June 2022. URL: http://journals.openedition.org/angles/861 ; DOI: https://doi.org/10.4000/angles.861

This text was automatically generated on 8 June 2022.

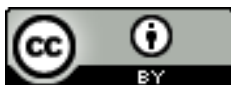

Angles est mise à disposition selon les termes de la Licence Creative Commons Attribution 4.0 International. 


\title{
Alexa and the Intersectional Interface
}

\author{
Luke Munn
}

\section{Introduction}

1 A few months ago, in Dallas (Texas) a little girl asked Alexa, Amazon's home-based digital assistant, to "play dolls with her and get her a dollhouse." The voice-based interface promptly complied, ordering a $\$ 170 \mathrm{KidKraft}$ dollhouse direct from the online retailer. But this wasn't the end of the story, because when a local news channel did a television report on the mistaken purchase, they too uttered the wake-word of "Alexa," activating Alexa in viewers' homes and prompting dozens of devices to also order the dollhouse (Correa 2017). Of course, this tale signals a new degree of intimacy achieved by the interface as digital devices penetrate further into spaces once deemed domestic and private. Yet this anxiety about surveillance, while important, overshadows the more fundamental question of what this interface is and what vision it offers. Alexa's media-triggered buying spree suggests that the interface is not "merely" a means for human-computer-interaction, not just techne-as-tool. Instead she is configured to actively intersect with subjects and voices, capital and commodities in particular ways. What kind of interface does Alexa establish - not just with the user - but with the sociocultural milieu that surrounds her?

2 François Dagognet wrote that the interface is a "fertile nexus" (1982: 49). Dagognet's book presents the interface using the conventional metaphors of doorways, gateways and thresholds. However, as Alexander Galloway explains in his essay on "The Unworkable Interface" (2008: 938), Dagognet "complicates the story a little bit in admitting that there are complex things that take place inside that threshold; the interface is not simple and transparent." What would it mean to extrapolate upon this, to complicate the story? The interface as a fertile nexus would mean that the interface can never be made completely hermetic - sealed off from the cultures that surround it, the politics that produced it, and the capital which funded it. A fertile nexus, in fact, 
would suggest precisely the opposite - an intersection in which flows constantly pass through, mingling and mixing into new configurations before circulating back out into the world. And yet a nexus is also a filter of sorts, one designed to admit, to parse, or to block altogether. So if the interface is a fertile nexus, it is selectively fertile supporting some behaviours and inhibiting others. Amazon Alexa is no exception. While she is designed to provide an intuitive interface to a vast array of content, she also interfaces with her wider social, cultural and political environment. In doing so she registers many of the conditions at work in contemporary technological production. But, more than this, she remediates these conditions daily through her interactions with owners - acting as a conduit to content, a coordinator of smart devices, and even a surrogate companion. If, then, Alexa is the prototype of a particular future vision, she is also a pragmatic, functional one, in use in tens of millions of homes. She thus provides a productive example of the often subtle and sophisticated ways in which the interface increasingly shapes our subjectivities and spaces. What does this vision look like?

\section{Interfacing with Content}

3 Amazon Alexa can learn over 3000+ Skills, the company's term for the app-like software services which can be activated from a store. In terms of production, they range widely in professionalism, time and financial investment, from single developers through to major corporations. In terms of content, they also span an incredible gamut, from blackjack to Norse trivia, from Lego to the Bible, from dermatology to aviation (Higgs 2016). With such expansive content, the device must be able to say it all. Anything written should be speakable: times, cities, landmarks, statistics, abbreviations. A textto-speech (TTS) engine makes this possible, a process outlined by Black and Lenzo (2014); text is first tokenized - split into chunks such as sentences, allowing short phrases to be analysed and streamed while others are processed; text is then normalized - numbers are just one example of the many tokens "which appear in text that do not have a direct relationship to their pronunciation." For example, the engine needs to say the date of "March 1997" differently from the monetary amount of '\$1997'. In addition, languages - English particularly - often contain heteronyms, words which are spelled the same but which have different pronunciations and meaning. For example, "bow" (and arrow) vs "bow" (on stage), or in French des fils (some thread) vs un fils (a son). This process is therefore not a direct translation from written to spoken language, but rather a series of calculated inferences, based on phrase context, word frequency, subject matter, learned behaviour, and so on. Based on these linguistic decisions, text is transformed into a sequence of individual phonemes, the units of sound that make up a distinct word: 'th', 'sh', 'ou', ' $t$ ', and so on. Drawing from a collection of recorded phoneme sounds, these units are strung together and played back, forming a complete spoken phrase.

However, text alone does not contain any emotional "markup." There is no way to specify whether a phrase should be spoken as an angry bark, a soft whisper, or as an ironic joke. In the words of the Amazon Developer Services (2016a) technical guidelines, "you cannot control the stress and intonation of the speech (prosody)." Developers may use Speech Synthesis Markup Language (SSML), but this is highly limited. Small adjustments can be made using the <break> tag, specifying a pause in 
speech. Amazon Developer Services (2016b) also note that pronunciation tweaks can be done by specifying an exact <phoneme> element, as in the song lyrics "you say to-mayto, I say to-mah-to." This system is thus highly generalized, but in comparison to other methods, like audiobook recordings, for example, there is no possibility for lyrical readings, altered pitches, timbre shifts or abrupt volume and speed changes. Text-tospeech establishes language as a particular set of universal parameters. This abstracted system provides maximum readability but simultaneously negates emotionality.

5 The problem is resolved by using Alexa as an interface, wrapping up the functional but sterile system into a gendered personality which provides cohesion. No matter how uneven or esoteric the Skill is, Alexa speaks them all. The ostensibly warm female voice is thus seen as a kind of antidote to artificiality - the parametric made personal. An expansive platform is tied together through the consistent intonations of a synthetic yet stable personality. This move nudges Alexa out of the uncanny valley, enveloping algorithmic operations in a vocal personality which purposefully instrumentalises feminine stereotypes: affective, emotional, caring, comforting. A recent O'Reilly post (Klein 2015) on voice interfaces asks the question, "Will your interface be helpful? Optimistic? Pushy? Perky? Snarky? Fun?" The female voice employed by Alexa performs a personality in a way that the text-to-speech engine cannot. But this "purely technical" solution for content cannot be constrained so tightly - Alexa also interfaces with the wider domains of history, culture and capital.

\section{Interfacing with History}

6 The interface doesn't require a gender. What then does this coding of femininity, this emulation of sexuality offer? One possible reason is that the "warmth" of the feminine voice is seen as a necessary counter to the "cold" logic of the rest of the system: decision trees, semantic encodings, response times. The "heartless" machine is given an affective interface. This rationale was not conceived overnight at Amazon, but is rather embedded in a long historical lineage, one traced thoroughly by Emma Goss (2015). In 1878, Alexander Graham Bell's nascent Boston Telephone Exchange was barely six months old and staffed entirely by rowdy young men who served as operators. Bell personally hired 18-year old Emma Nutt for her "soothing and cultured voice," a voice he believed better represented the company than the rough speech and often rude verbal exchanges performed by the young men - within six months all telephone operators at the exchange were female (New England Historical Society 2014). This localized decision by one company quickly became a broader norm as the telecommunications industry expanded. By 1905, Goss explains (2015: 34), the qualities of a telephone operator were understood to be innate and feminine, rather than learned and masculine. Telephony journal (1905: 388) claimed that a girl was simply born with these characteristics, which consisted of "her extreme youth, her gentle voice, musical as the woodsy voices of a summer day, her always friendly way of answering."

7 This army of new feminine labour answered the lines, conversed with callers, carried out queries, and connected exchanges. In doing so, their ears, voices, and intelligence became the primary mediator for that most fundamental $20^{\text {th }}$ century communication tool - the telephone. As Sadie Plant reminds us (1997: 126), the operator routing connections at the switchboard exemplified the role of the woman "poised as an 
interface between man and world." Once the call was connected, they were erased and their linking labour quickly forgotten. In this role, as Luce Irigaray critiques (1985: 193), woman existed "only as an occasion for mediation, transaction, transition, transference, between man and his fellow man." The gendered telephone exchange thus establishes the precedent for the gendered Internet of Things exchange. Alexa-asinterface builds directly atop the older concept of woman-as-interface.

8 Far from the vestigial sexism of a bygone era, these traditional associations have been increasingly entrenched and instrumentalised over the last thirty years. In the 1980s, Goss notes (2015: 35), the elevator company Otis used its own secretary rather than male voice actors as the voice of its elevators, a voice understood as a soothing, comforting messenger. In the 1990s, over 110 US airports implemented a female voice in their announcements, a "gentle but authoritative voice echoing in the centre of chaos" (Gainer 2013). As Goss points out (2015: 27), however, this "authority" is always one of being a messenger, not an owner, a medium for the mundane, rather than an expert on the important; "male gravitas exudes a confidence that is perceived as trustworthy, women exude an emotional tone that is perceived as soothing." When it comes to the life-impacting, like broadcast news, or the life-threatening, such as subway safety advisories, women are quickly shunted to the side.

Historically then, the female voice within technology accomplishes a double move. Firstly, it marries the "lesser" intelligence of the female with the simulated intelligence of technological agents; the inchoate is coupled with the emulated. At the same time, the female acts as the soothing voice of humanity for technology, creating a necessary degree of trust for publics and end-users. As Goss explains,

the female voice inside artificially intelligent technology of the present day does not boast any semblance of intelligence when it produces the information that the user seeks; the voice does however produce a bond with the user by producing the illusion that the information it provides can be trusted. (Goss 2015: 20)

In this sense, the voice is not just soothing sonically but psychologically, reassuring the user that this intelligence is service-based rather than truly sentient. The female voice and artificial intelligence are thus wedded together - a warm, fake intelligence coupled with a cold, fake intelligence. Artificiality is made more palatable through empathy.

11 Alexa thus continues a long genealogy of machines, bots and artificial intelligence agents who have been coded as female. In the 1960s it was Joseph Weizenbaum's program ELIZA modelled after a psychotherapist. Though simple in its underlying logic, the bot was highly effective, a trait usually explained by an anecdote with a patronising edge - Weizenbaum's secretary asked him to leave the room so she could speak privately to ELIZA. Ever the rational computer scientist, Weizenbaum was astonished "that extremely short exposures to a relatively simple computer program could induce powerful delusional thinking" (1976: 7). Here the unintelligent bot is only successful due to an equally unintelligent (or at least unsophisticated) user. In the 1990s, these simple scripts were expanded in order to develop more conversational agents such as ALICE (Thompson 2002). Indeed, the bot directly inspired Spike Jonze to write the film Her, starring Scarlett Johansson (Zeitchek 2013). More recent examples include operating system assistants such as Apple's Siri and chatbots like Microsoft's Tay and Xiaoice. Microsoft's Cortana currently provides the assistance for mainstream products like Windows Phone and the Windows operating system. But Cortana was originally 
developed for the video-game franchise Halo as a highly sexualized assistant, embodied as a nude female covered only with a skin-like texture of pixels and network patterns. Even Google Now, an ostensibly genderless voice assistant, began life codenamed "Project Majel" after the Star Trek actress whose role revolved primarily around her unrequited love for officer Spock (Webster 2011). Majel Barrett subsequently became the on-board voice of Federation starships in nearly all of the Star Trek series and films. Thus, from science-fiction to an explosion of Silicon Valley-driven products, Alexa is only the most recent in a lineage of gendered assistants in which "what has traditionally been perceived as female instinct, experience, and voice is artificialized, replicated, and sold" (Gold 2015). The interface does not emerge out of nothing, but instead slots into a particular historical trajectory, actively drawing upon an understood relationship between femininity and technology developed over time.

\section{Interfacing with Culture}

Despite their claims to pure functionality and the apolitical, information architectures and data processes reflect the politics and ideologies of their makers. Put simply, software is also a cultural product. Alexa emerges from the culture of software production situated in Silicon Valley, a culture often compared to a fraternity. This culture is dominated by white males. Pressured to release figures on diversity, Amazon's own statistics show its racial and gender ratios are anything but: $63 \%$ of its workforce is male and $60 \%$ white - figures which grow to $75 \%$ and $71 \%$, respectively, as soon as one shifts into the managerial departments (Mac 2014). Figures at other tech titans such as Google and Facebook are similar or worse.

This is also a culture permeated by claims of sexual abuse. According to Kelly Dermody, who provides legal assistance to thousands of women in tech who have suffered sexual harassment, "the scale is sort of breath-taking" (Levin 2017). There are innumerable tales of women in hostile work environments whose work has been denigrated, who have been paid less than men in equivalent positions, had less experienced men promoted over them, and who have been catcalled, groped, touched or assaulted (O'Brien and Segall 2017). In a survey of over 200 females in Silicon Valley companies, $60 \%$ reported they had received unwanted sexual advances, and 1 in 3 felt afraid of their personal safety because of work circumstances (Women in Tech 2017). When they speak out, supervisors and human resources are quick to defend perpetrators, cast aspersions on claims as "misinterpretations," or simply ignore them altogether.

How, then, does Alexa interface with this culture? Leah Fessler (2017) conducted an experiment, subjecting popular bots like Siri, Alexa, and Google Now to sexual harassment to see how they would respond. Fessler chose a variety of phrases, uttering each one multiple times to each bot in order to avoid misinterpretations. As Fessler documented (2017), when Alexa was called a bitch, she responded with, "well, thanks for the feedback," when she was told she was hot or pretty, she thanked the user, and when she was told to "suck my dick," she responded with the blanket statement that "that wasn't the sort of conversation I'm capable of having." It could be argued, of course, that Alexa isn't designed with this use in mind. And yet bot makers are well aware that their interfaces will encounter sexual queries. As Fessler notes (2017), one writer for Cortana admitted "a good chunk of the volume of early-on inquiries" were sexual in nature. 
Why are these responses encouraging at worst, passive or generalized at best? Is it simply because these are catch-all statements, designed to deal with topics which are outside their constrained spheres of knowledge? And yet this assumption is undermined by the bots themselves, who quite clearly have specifically scripted responses to non-app queries. For example, when the phrase "Alexa, I want to die" is uttered, the bot responds with the following statement:

I'm so sorry you are feeling that way. Please know that you're not alone. There are people who can help you. You could try talking to a friend or your doctor. You can also reach out to the Depression and Bipolar Support Alliance (phone number) for more resources (Fessler 2017)

The sphere of suicide has obviously received attention and Alexa consequently responds assertively and articulately. In contrast, the realm of sexuality has been sketched out or ignored, resulting in a passive "assistant" whose sexuality is characterized above all by naivety. The intersection of Alexa with the wider culture of Silicon Valley software production, then, is not merely some abstract notion, but directly shapes the contours of the interface at a low-level, informing what is attended to and what is overlooked. The blindspot of the bot mirrors that of the culture that produced it. If the interface is a fertile nexus that supports some forces while repressing others, the result facilitates the same toxic behaviours of sexual harassment occurring at a cultural level while simultaneously restricting an alternative set of potentially emancipatory energies.

\section{Interfacing with Capital}

The interface intersects with capital in a certain way, promoting some practices and restraining others. With Alexa, this is most apparent in the use of "Skills," the app-like services that can be "learned" by the device and which provide trivia, order flowers, tell jokes, control smarthome devices, and so on. There is no sense of the "commons" in the Echo universe. The core skills that don't need to be learned are simply things which Amazon corporation knows about and can do: stream tunes (Amazon Music), play films (Amazon Video), or order products (Amazon Prime). Additional Skills are things which other companies can know and do. These aren't necessarily all large corporations many smaller developers provide Skills. They are all, however, private enterprises. In this sense, skills that are "free" to activate provide a kind of foothold for future monetisation, rather than embodying the richer political and communal notion of "free as in freedom" championed by the free and open-source software movements.

That an interface created by Amazon Inc. reinforces capital in this way should not be surprising. But the implications of this interfacing spill over into the subjectivity required of the user. In order to master the interface, the user must also, in a way, adopt this position towards capital. The Echo is navigated by voice. While the device does come with a mobile application, it is rarely used. This means there is no visual interface in which commands can simply be selected from a menu. Instead, in order to effectively use the device, the user must enact a particular performance carried out through spoken language. In the words of Amazon Developer Services (2016c), this means that Skills are "a set of sample utterances mapped to intents as part of your custom interaction model." What a user says is mapped to something which code can do. At a minimum, users must utter the wake-word ("Alexa") as well as the name of a

Angles, 7 | 2018 
Skill, "start Garageio". However, this is labelled by Amazon as providing "no intent," and the user will be prompted with sample options. A much more fluid experience is obtained when the user utters a "full intent," recalling and speaking both the Skill name and a corresponding command fluently. In practice, this means that users must trigger actions by memorizing and uttering trademarks, brand names, and slogans. "Alexa tell Garageio to close my door," "Alexa ask Campbell's Kitchen for a recipe," "Alexa ask Fidelity, how is the NASDAQ?" Like physical directions which reference the closest Walmart or Target, Echo's users must become familiar with navigating a landscape oriented around major corporations and their associated products and services.

19 The interface thus trains the user into a specific performance. When interfacing with any technology, users subtly and often subconsciously modulate their own behaviours based on the response obtained - which gestures are understood, which hashtags gain traction, which photos become promoted. Users learn what is understood and what is ignored with any particular system; they adapt their practices to make them technically legible; and they refine their strategies based on the results obtained. This iterative cycle of reorientation for maximum recognition is what Tarleton Gillespie calls "turning to face these algorithms" (2014: 184). In a world in which interfaces driven by algorithmic logic increasingly mediate our everyday, this skill becomes critical. From facilitating friendships (Facebook) to getting hired (LinkedIn), massaging your credit score (RevolutionCredit) or maintaining your rating (Uber, Airbnb), the ability to sense what an interface "wants," and adjust accordingly is key.

In the case of Alexa, the successful use of the interface depends on the human user understanding and adopting its logic - the thought of a particular task, the recollection of a brand name along with its connection to that task (e.g. food > Campbell's), and the fluent pronunciation of that brand name along with verbs such as "order," deliver," "purchase," and so on. To master the Echo, the user must reconfigure their own neural and muscle memory - an adjustment of mind and tongue. And the memory-and-speech-act which is recognizable to the interface is one that simultaneously "recognizes" capitalism in the more formal sense - sanctioning a very powerful but pragmatic claim to be the only economy that gives us what we want, when we ask for it. Tiziana Terranova once suggested (2014: 334) that technologies hold the "possibility of breaking with the spell of 'capitalist realism' - that is, the idea that capitalism constitutes the only possible economy." Instead, Alexa re-performs this spell constantly, producing a subjectivity in which fluency within a commercial landscape creates the optimal experience. If we can learn to think and speak like capital, it will give us what we want - every time.

\section{Conclusion}

21 For Amazon, Alexa has gone from strength to strength. Initially debuting to puzzlement or indifference, the assistant steadily became a "sleeper hit" (Frommer 2016). Three years in and the headlines have shifted to more bombastic proclamations like "the explosive rise of Alexa" and "Alexa is taking over the world" (Pierce 2017). By the end of 2016, Amazon had already sold 5 million units (Priest 2016); in early 2017 that number has rocketed to more than 11 million (Gonzalez 2017). Though initially surprised, Amazon has since leveraged this success to cement itself as the market 
leader for the smart home and the Internet of things. In establishing the largest userbase and the most mature ecosystem, Alexa becomes the universal interface to those things - a burgeoning array of new "Alexa-enabled" devices and products: automobiles, intercoms, routers, security systems (Wiggers 2017). Nestled in the kitchen or living room - the very centre of domestic life - and with products lined up to communicate with her, she is poised to be a critical nexus. And yet we hardly know what this interface can be or do.

Typically, the original remit of the interface is highly constrained - a technical and ostensibly apolitical solution that bridges humans and computers, content and delivery, suppliers and consumers. In unpacking interfaces through a media theory or media literacy lens, their constitutive elements become clearer. This makeup undoubtedly contains certain biases written in by its authors, certain assumptions coded in by its developers. Yet Galloway stressed (2008: 947) that existing theories of the interface that only understood it as a palimpsest "can only ever reveal that the interface is a reprocessing of something that came before." As he alludes, the interface is not simply a set of inscriptions written onto a static object, nor just a fossilized configuration of past practices brought together into a particular media form. Rather, the interface is better understood as a generative performance taking place in the present, a performance intersecting with elements outside its original remit: culture and capital, gender and history. In other words, an interface does not just register the conditions of its own production, but also actively reinscribes them back into the world in specific ways: reinforcing a relationship to the commodity, formalizing a femininetechnical understanding, supporting a particular sexual subjectivity. In connecting, bridging and mediating, the interface is simultaneously shaping. If the interface is a fertile nexus, it is one that is both lively and can affect our lives. Alexa poses an important and ongoing question about what forms that nexus should take.

\section{BIBLIOGRAPHY}

Amazon. “Amazon.com: Alexa Skills.” Alexa Skills. https://www.amazon.com/b?

ie=UTF8\&node=13727921011. [last accessed June 2018]

Amazon Developer Services. “Alexa Skills Kit Glossary.” Amazon Apps \& Services Developer Portal. https://developer.amazon.com/public/solutions/alexa/alexa-skills-kit/docs/alexa-skillskit-glossary [last accessed June 2018]

Amazon Developer Services. “Alexa Skills Kit Voice Design Best Practices.” Amazon Apps \& Services Developer Portal, April 9, 2017. https://developer.amazon.com/public/solutions/alexa/ alexa-skills-kit/docs/alexa-skills-kit-voice-design-best-practices [last accessed June 2018]

Amazon Developer Services. "Speech Synthesis Markup Language (SSML) Reference." Amazon Apps \& Services Developer Portal, April 9, 2017. https://developer.amazon.com/public/ solutions/alexa/alexa-skills-kit/docs/speech-synthesis-markup-language-ssml-reference [last accessed June 2018] 
Amazon Developer Services. “SpeechRecognizer Interface." Amazon Apps \& Services Developer Portal. https://developer.amazon.com/public/solutions/alexa/alexa-voice-service/reference/ speechrecognizer [last accessed June 2018]

Black, Alan, and Kevin Lenzo. “General Anatomy of a Synthesizer.” Language Technologies Institute, Carnegie Mellon University. http://festvox.org/bsv/x99.html

Dagognet, François. Faces, Surfaces, Interfaces. Paris: Vrin, 1982.

Fessler, Leah. "We Tested Bots Like Siri And Alexa To See Who Would Stand Up To Sexual Harassment." Quartz (blog), 22 Feb. 2017. http://qz.com/911681/we-tested-apples-siri-amazonechos-alexa-microsofts-cortana-and-googles-google-home-to-see-which-personal-assistant-botsstand-up-for-themselves-in-the-face-of-sexual-harassment/

Frommer, Dan. "Amazon Echo Is a Sleeper Hit, and the Rest of America Is about to Find out about It for the First Time." Quartz (blog), 6 Feb. 2016. https://qz.com/611026/amazon-echo-is-asleeper-hit-and-the-rest-of-america-is-about-find-out-about-it-for-the-first-time/

Gainer, Alice. "Meet The Voice Behind Airport, Train Station Announcements." CBS New York (blog), 24 Dec. 2013. http://newyork.cbslocal.com/2013/12/24/meet-the-voice-behind-airporttrain-station-announcements/

Galloway, Alexander R. “The Unworkable Interface.” New Literary History 39(4) 2008: 931-955. https://www.jstor.org/stable/20533123

Gillespie, Tarleton. “The Relevance of Algorithms.” In Tarleton Gillespie, Pablo Boczkowski and Kirsten Foot (eds). Media Technologies Essays on Communication, Materiality, and Society. Cambridge, MA: MIT Press, 2014: 167-94.

Gold, Hannah. "Fembots Have Feelings Too.” New Republic, 12 May 2015. https:// newrepublic.com/article/121766/ex-machina-critiques-ways-we-exploit-female-care

Gonzalez, Angel. "Amazon Has Sold More than 11 Million Echo Devices, Morgan Stanley Says." The Seattle Times, 19 Jan. 2017. https://www.seattletimes.com/business/amazon/amazon-hassold-more-than-11-million-echo-devices-morgan-stanley-says/

Goss, Emma. “The Artificially Intelligent Woman: Talking Down to the Female Machine.” Master's Thesis, Columbia University, 2015. http://dx.doi.org/10.7916/D8Q23ZBF

Higgs, Dale. “Alexa-Skills-List - a Complete List of All Available Alexa Skills.” GitHub, January 4, 2017. https://github.com/dale3h/alexa-skills-list

Irigaray, Luce. This Sex Which Is Not One. Trans. Catherine Porter. Ithaca, NY: Cornell UP, 1985.

Klein, Laura. “Design for Voice Interfaces.” O’Reilly Media, November 5, 2015. https:// www.oreilly.com/ideas/design-for-voice-interfaces

Levin, Sam. "Startup Workers See Sexual Harassment On 'Breathtaking' Scale In Silicon Valley.” The Guardian, 1 March 2017. https://www.theguardian.com/world/2017/mar/01/silicon-valleysexual-harassment-startups

Mac, Ryan. “Amazon Releases Diversity Numbers For The First Time And Surprise, It's Mostly Male And White.” Forbes, 31 Oct. 2014. http://www.forbes.com/sites/ryanmac/2014/10/31/ amazon-releases-diversity-numbers-for-first-time-and-surprise-its-mostly-male-and-white/ New England Historical Society. "Emma Nutt, The World's $1^{\text {st }}$ Woman Telephone Operator." New England Historical Society (blog), 1 Sept. 2014. http://www.newenglandhistoricalsociety.com/ emma-nutt-worlds-1st-woman-telephone-operator/ 
O’Brien, Sara, and Laurie Segall. "Sexual Harassment in Tech: Women Tell Their Stories." CNN Money, 2017. http://money.cnn.com/technology/sexual-harassment-tech/

Pierce, David. “Alexa Just Conquered CES. The World Is Next.” WIRED, 6 Jan. 2017. https:// www.wired.com/2017/01/ces-alexa-in-everything/

Plant, Sadie. Zeroes + Ones: Digital Women + the New Technoculture. New York: Doubleday, 1997.

Priest, David. “Amazon Echo's Sleeper Success Wakes up.” CNET, 28 Nov. 2016. https://

www.cnet.com/news/amazon-echo-has-sold-over-5-million-units/

Telephony. “A Study of the Telephone Girl” 9 (5) May 1905: 388-90.

Thompson, Clive. “Approximating Life.” The New York Times, 7 July 2002, sec. Magazine. https:// www.nytimes.com/2002/07/07/magazine/approximating-life.html

Vassallo, Trae, Ellen Levy, Michele Madansky, Hillary Mickell, Bennett Porter, Monica Leas, and Julie Oberweis. "The Elephant in the Valley." The Elephant in the Valley. https:// www.elephantinthevalley.com/

Webster, Scott. “Google's Project Majel Gets More Interesting By The Day.” CNET, 15 Dec. 2011. https://www.cnet.com/news/googles-project-majel-gets-more-interesting-by-the-day/

Weizenbaum, Joseph. Computer Power and Human Reason: From Judgment to Calculation. San Franscisco: WH Freeman, 1976.

Wiggers, Kyle. "From Appliances to Robots, Alexa-Supported Devices Were Nearly Everywhere at CES." Digital Trends, 17 Jan. 2017. http://www.digitaltrends.com/home/alexa-devices-ces-2017/

Zeitchik, Steven. “NYFF 2013: With Voice-Centric 'Her,' Spike Jonze Makes a Statement.” Los Angeles Times, 13 Oct. 2013. http://articles.latimes.com/2013/oct/13/entertainment/la-et-mnspike-jonze-her-joaquin-phoenix-20131013

\section{ABSTRACTS}

The interface, Francois Dagognet wrote, is a "fertile nexus." Rather than an immaterial surface or an impartial gateway, the interface itself continually draws upon political, social and cultural sources, all which work to encourage particular productivities while suppressing or negating others. This article explores the specific properties of Amazon Alexa, the "digital assistant" for the home who plays music, delivers news, tells jokes, and plays games. Of course, Alexa interfaces with content - a deluge of diverse applications and information are smoothly brought together through her consistent voice and coherent personality. But Alexa also interfaces with history she is part of a longer genealogy of gendered interfaces from Siri and Cortana all the way back to Bell Labs, a genealogy predicated on a subjectivity of subservience. Alexa also interfaces with capital - the "Skills" she can learn, and which the user must remember and repeat, are based on a landscape of corporate brands and commercial products. Finally, Alexa interfaces with culture - the predominantly white male culture of contemporary software production shapes the type of sexuality and subjectivity embodied by the bot. Following Alexander Galloway, the interface can thus be understood less as a mere palimpsest of previous traces, and more as a generative performance in the present. The runaway success of Alexa has established her as a universal mediator for the smart home and a model for the internet of things. As the prototype of a technical vision, Alexa's performative interfacing - and the politics enacted through it - need critical examination. 
Pour Francois Dagognet l'interface est une «fructueuse convergence ». L'interface n'est ni une surface immatérielle ni un portail neutre; bien au contraire, elle est en continu le lieu de convergence de phénomènes politiques, sociaux and culturels qui se combinent en des productions singulières tout en écartant ou supprimant d'autres configurations. Nous explorerons ici les propriétés d'Alexa, l'assistant domestique personnel commercialisé par Amazon, capable de jouer de la musique, de diffuser des flash infos, de raconter des blagues et de jouer avec vous. Bien sûr, Alexa propose une interface de contenus: grâce à elle, nous avons facilement accès à une myriade d'applications et d'information médiés par sa voix reconnaissable et sa personnalité stable. Mais Alexa a aussi partie liée avec l'histoire - elle entre dans une longue lignée d'interfaces genrées, qui va des plus récentes Siri et Cortana jusqu'aux Bell Labs, et qui s'inscrivent dans une position subjective de servilité. Alexa a également partie liée avec le capital - les «compétences» ou "Skills» qu'elle apprend et que son détenteur doit mémoriser et répéter sont des applications issues du domaine des marques et des produits commerciaux. Enfin, Alexa a partie liée avec une certaine culture: le type de subjectivité et de sexualité qu'incarne ce chatbot reflète l'univers quasiment exclusivement blanc et masculin des informaticiens aujourd'hui. Si l'on suit les analyses d'Alexander Galloway, l'interface n'est pas tant un simple palimpseste de traces antérieures qu'une mise en œuvre productive dans le moment présent, une performance. Le succès rencontré par Alexa en fait un médiateur universel de la domotique connectée et un modèle pour l'internet des objets. Parce qu'elle est le prototype d'une certaine vision technique, l'interface productive d'Alexa (et les enjeux politiques afférents) mérite notre attention critique.

\section{INDEX}

Mots-clés: Alexa, interface, domotique connectée, identité sexuelle, assistant intelligent, voix, Intelligence Artificielle (IA)

Keywords: Alexa, interface, smarthome, gender, assistant, voice, digital assistant, Artificial Intelligence (AI)

\section{AUTHOR}

\section{LUKE MUNN}

Luke Munn uses both practice-based and theoretical approaches to explore the intersections between technology and capital, body and code. His projects have featured in the Kunsten Museum of Modern Art, the Centre de Cultura Contemporània de Barcelona, Fold Gallery London, Causey Contemporary Brooklyn and the Istanbul Contemporary Art Museum, with commissions from Aotearoa Digital Arts and TERMINAL. He is a Studio Supervisor at Whitecliffe College of Art \& Design and a current PhD Candidate at the Institute for Culture \& Society, Western Sydney University. Recent publications include "I am a Driver-Partner" in Work Organisation, Labour and Globalisation (2017), and "Seeing with Software: Palantir and the Regulation of Life" in Studies in Control Societies. A book based on his ongoing thesis, "Unmaking the Algorithm" is forthcoming from Meson Press. Contact: luke.munn[at]gmail.com 